\title{
The Modified Quadrature Method for solving Volterra Linear Integral Equations
}

\author{
Mahmood A. Shamran*
}

Sami Abdulla Abid**

Received 15, January, 2014

Accepted 30, March, 2014

\begin{abstract}
:
In this paper the modified trapezoidal rule is presented for solvingVolterra linear Integral Equations (V.I.E) of the second kind and we noticed that this procedure is effective in solving the equations. Two examples are given with their comparison tables to answer the validity of the procedure.
\end{abstract}

Key words: trapezoidal rule , least square , Volterra linear Integral Equations

\section{Introduction:}

The quadrature methods are bases of every numerical method for finding solution of integral equations [1].

The problem of numerical quadrature arises when the integration can not be carried out exactly or when the function is known only at a finite number of data. Furthermore numerical quadrature methods are primary tools, used by engineers and scientists to obtain approximate answers for definite integrals that cannot be solved analytically [2].

The main purpose of this paper is to use Bernstein polynomials to derive the composite modified trapezoidal rule of first order. Moreover, This method is used for solving Volterra linear integral equations of the second kind. Integral equations are solved by interpolation and Gauss quadrature method. [3]. (V.I.E) of the 2nd kind with convolution kernal are solved by using the Taylor expansion method. [4]. Linear integral equations are solved with repeated Trapezoidal quadrature method. [5].

Integral equation in Urysohnform are solved numerically [6]. Fredholm integral eigen value problems are solved by alternate Trapezoidal quadrature method.[7]. Collocation method is used for solving Fredholm and Volltera integral equation.[8]

\section{The modified Trapezoidal rule of first order [9]}

Polynomials are useful mathematical tools as they are simply defined, can be calculated quickly by a computer system and represent a tremendous variety of functions. They can be differentiated and integrated easily, and can be pieced together to form spline curves that can approximate any function to any accuracy desired. Most students are introduced to polynomial at a very early stage in their studies of mathematics, and would probably recall them in the form below $P(t)=a_{n} t^{n}+a_{n-1} t^{n-1}+\cdots+a_{1} t$

Which represents a polynomials linear combination of certain elementary polynomials $\left\{1, \mathrm{t}, \mathrm{t}^{2}, \ldots, \mathrm{t}^{\mathrm{n}}\right\}$.

In general, any polynomial function that has degree less than or equal to $\mathrm{n}$, can be written in this way and the reasons are simply.

The set of polynomials of degree less than or equal to $n$ forms a vector space. Polynomials can be added together, can be multiplied by a

\footnotetext{
*University of Baghdad, College of Science for Women, Mathematics department **University of Diala, College of Administration and Economy
} 
scalar and all the vector space properties hold.

The set of functions $\left\{1, t, t^{2}, \ldots, t^{n}\right\}$ form a basis for this vector space-that is, any polynomial of degree less than or equal to $\mathrm{n}$ can be uniquely written as a linear combinations of these functions.
This basis commonly called the power basis is only one of an infinite number of bases for the space of polynomials. Consider Bernstein polynomials given by the following equation:-

$$
\sum_{k=0}^{n} f\left(\frac{k}{n}\right)\left(\begin{array}{l}
n \\
k
\end{array}\right) x^{k}(1-x)^{n-k}
$$

Where $\mathrm{f}$ is a function, $\mathrm{k}=0,1, \ldots, \mathrm{n}$ Then:-

$$
\begin{aligned}
& P(x)=f\left(\frac{0}{n}\right)\left(\begin{array}{l}
n \\
0
\end{array}\right) x^{0}(1-x)^{n-0}+f\left(\frac{1}{n}\right)\left(\begin{array}{l}
n \\
1
\end{array}\right) x(1-x)^{n-1} \\
& +f\left(\frac{2}{n}\right)\left(\begin{array}{l}
n \\
2
\end{array}\right) x^{2}(1-x)^{n-2}+f\left(\frac{3}{n}\right)\left(\begin{array}{l}
n \\
3
\end{array}\right) x^{3}(1-x)^{n-3} \\
& +\cdots+f\left(\frac{n}{n}\right)\left(\begin{array}{l}
n \\
n
\end{array}\right) x^{n}(1-x)^{n-n} \\
& =f(0)(1-x)^{n}+f\left(\frac{1}{n}\right)\left(\frac{n !}{1 !(n-1) !}\right) x(1-x)^{n-1}+ \\
& f\left(\frac{2}{n}\right)\left(\frac{n !}{2 !(n-2) !}\right) x^{2}(1-x)^{n-2}+ \\
& f\left(\frac{3}{n}\right)\left(\frac{n !}{3 !(n-3) !}\right) x^{3}(1-x)^{n-3}+\cdots+f(1) x^{n} \\
& =f(0)(1-x)^{n}+n f\left(\frac{1}{n}\right) x(1-x)^{n-1}+ \\
& \frac{n(n-1)}{2 !} f\left(\frac{2}{n}\right) x^{2}(1-x)^{n-2}+ \\
& \frac{n(n-1)(n-2)}{3 !} f\left(\frac{3}{n}\right) x^{3}(1-x)^{n-3}+\cdots+f(1) x^{n}
\end{aligned}
$$

By substituting $\mathrm{n}=1$. Then

$$
\begin{aligned}
\mathrm{p}(\mathrm{x})= & \mathrm{f}(0)(1-\mathrm{x})+\mathrm{f}(1) \mathrm{x}(1-\mathrm{x})^{0} \\
& =\mathrm{f}(0)(1-\mathrm{x})+\mathrm{f}(1) \mathrm{x}
\end{aligned}
$$

Let

$$
\begin{aligned}
& \mathrm{y}_{0}=\mathrm{f}(0) \text { and } \quad \mathrm{y}_{1}=\mathrm{f}(1) \text { then } \\
& \mathrm{P}(\mathrm{x})=\mathrm{y}_{0}(1-\mathrm{x})+\mathrm{y}_{1} \mathrm{x}
\end{aligned}
$$

By integrating both sides of above equation from ( 0 to1) one can get:-

$$
\begin{aligned}
\int_{0}^{1} \mathrm{f}(\mathrm{x}) \mathrm{dx} & \simeq \int_{0}^{1} \mathrm{p}(\mathrm{x}) \mathrm{dx} \\
& =\frac{1}{2}\left(\mathrm{y}_{0}+\mathrm{y}_{1}\right)
\end{aligned}
$$

Now by using the transformation.

$$
\mathrm{x}=\mathrm{a}+\mathrm{t}(\mathrm{b}-\mathrm{a}), \mathrm{h}=\frac{\mathrm{b}-\mathrm{a}}{1}
$$

then from the above equation, one can get

$$
\int_{a}^{b} f(x) d x=\frac{h}{2}\left[f_{0}+f_{1}\right]
$$

This formula is the modified trapezoidal rule of first order .

\section{1-The composite modified}

\section{Trapezoidal Rule of first order :-}

It can be derived by extending the modified trapezoidal rule of first order .This procedure begins by dividing [a , b] into $\mathrm{n}$ subintervals and applying the modified trapezoidal rule of first order over each interval then the sum of the results obtained for each interval is the approximate value of integral, that is 


$$
\int_{a}^{b} f(x) d x=\int_{a}^{a+h} f(x) d x+\int_{a+h}^{a+2 h} f(x) d x+\cdots+\int_{a+(n-2) h}^{a+(n-1) h} f(x) d x+\int_{a+(n-1) h}^{b} f(x) d x
$$

where $h=\frac{b-a}{n}$

$$
\begin{aligned}
& \quad=\frac{h}{2}[f(a)+f(h)]+\frac{h}{2}[f(a+h)+f(a+2 h)]+\ldots+\frac{h}{2}[f(a+(n-2) h)+ \\
& f(a+(n-1) h)]+\frac{h}{2}[f(a+(n-1) h)+f(b)] \\
& =\frac{h}{2}[f(a)+2 f(a+h)+2 f(a+2 h)+\cdots+2 f(a+(n-2) h)+2 f(a+ \\
& (n-1) h)+f(b)](3) \\
& =\frac{h}{2}\left[f(a)+2 \sum_{j=1}^{i-1} f\left(x_{j}\right)+f(b)\right]
\end{aligned}
$$

This formula is said to be the composite modified Trapezoidal Rule of the first order.

\section{Numerical solution for solving the one-dimensional Volterra :linear integral equation using the composite modified trapezoidal rule :-}

The composite modified trapezoidal of first order for finding

$$
\begin{aligned}
& \int_{a}^{b} f(x) d x \text { is } \int_{a}^{b} f(x) d x \\
& \simeq \frac{h}{2}[f(a) \\
&+2 \sum_{j=1}^{i-1} f\left(x_{j}\right) \\
&+f(b)](5)
\end{aligned}
$$

where $\mathrm{n}$ is the number of subintervals of the interval $[a, b]$ and $h=\frac{b-a}{n}$.In this section this rule is used to solve the one-dimensional Volterra linear equations of the second kind given by :

$$
\begin{aligned}
u(x)=f(x)+ & \lambda \int_{a}^{x} K(x, y) u(y) d y, x \\
& \geq a(6)
\end{aligned}
$$

First, the interval $[a, b]$ is divided into nsubintervals, $\left[\mathrm{x}_{\mathrm{i}}, \mathrm{x}_{\mathrm{i}+1}\right]$, $\mathrm{i}=0,1, \ldots, \mathrm{n}-1$,

Such that $x_{i}=a+i h, i=0,1, \ldots n$ where $\mathrm{h}=\frac{\mathrm{b}-\mathrm{a}}{\mathrm{n}}$ so the problem here is to find the solution of equation (6) at each $\mathrm{x}_{\mathrm{i}}, \mathrm{i}=0,1, \ldots \mathrm{n}$. Then by setting $x=x_{i}$ in equation (6) one can get:-

$$
\begin{aligned}
& \mathrm{u}\left(\mathrm{x}_{\mathrm{i}}\right) \\
& =\mathrm{f}\left(\mathrm{x}_{\mathrm{i}}\right) \\
& +\lambda \lambda \int_{\mathrm{a}}^{\mathrm{x}_{\mathrm{i}}} \mathrm{k}\left(\mathrm{x}_{\mathrm{i}}, \mathrm{y}\right) \mathrm{u}(\mathrm{y}) \mathrm{dy}, \quad \mathrm{i} \\
& =0,1, \ldots, \mathrm{n}(7)
\end{aligned}
$$

Next we approximate the integral appeared in the right hand side of the above integral equation by the composite modified trapezoidal rule to obtain $\mathrm{u}_{0}=\mathrm{f}_{0}$

$$
\begin{aligned}
u_{i}=f_{i}+\frac{\lambda \lambda h \lambda}{2} & k\left(x_{i}, x_{0}\right) u_{0} \\
& +\lambda \lambda \lambda h \sum_{j=1}^{i-1} k\left(x_{i}, x_{j}\right) u_{j} \\
& +\frac{\lambda \lambda h}{2} k\left(x_{i}, x_{i}\right) u_{i}
\end{aligned}
$$

therefore 


$$
\begin{aligned}
u_{i}=f_{i}+\lambda \lambda h \lambda & \sum_{j=1}^{i-1} K\left(x_{i}, x_{j}\right) u_{j} \\
& +\frac{\lambda \lambda \lambda h}{2} K\left(x_{i}, x_{i}\right) u_{i}
\end{aligned}
$$

To illustrate these methods, the following examples are considered:-

\section{Example (1):-}

Consider the one-dimensional Volterra linear integral equation of the second kind is:-

$$
u(x)=x+\frac{1}{5} \int_{0}^{x} x y u(y) d y \quad 0 \leq x \leq 2
$$

If it is solved by successive approximation method taking the zero ${ }^{\text {th }}$ approximation

Then

$$
\mathrm{u}_{0}=\mathrm{x}
$$

$$
\begin{aligned}
& u_{1}=x+\frac{1}{5} x \int_{0}^{x} y^{2} d y=x+\frac{1}{15} x^{3} \\
& =x\left(1+\frac{x^{3}}{15}\right) \\
& u_{2}=x+\frac{1}{5} x \int_{0}^{x}\left(y^{2}+\frac{1}{15} y^{5}\right) d y \\
& \qquad=x+\frac{1}{5} x\left(\frac{x^{3}}{3}+\frac{1}{90} x^{6}\right) \\
& u_{1}=222466 \\
& u_{3}=0.6807463739=0.933008 \\
& u_{6}=1.5663078835 \\
& u_{9}=3.4362093627 \quad u_{7}=2.0074989 \\
& \text { Second if we divide the interval }[0,2] \\
& \text { in } 18 \text { subintervals, such that xi=i }, i= \\
& 0,1,2, \ldots, 18 \quad \text { then the equation }(6) \\
& \text { becomes }
\end{aligned}
$$$$
\mathrm{u}_{7}=2.0074989850
$$

Clearly

$$
=x\left(1+\frac{x^{3}}{15}+\frac{1}{2 !}\left(\frac{x^{3}}{15}\right)^{2}\right)
$$

$$
\begin{array}{r}
u_{n}(x)=\sum_{i=0}^{n} \frac{\left(\frac{x^{3}}{15}\right)^{i}}{i !} \\
u(x)=\lim _{n \rightarrow \infty} u_{n}(x)=x e^{\frac{x^{3}}{15}}
\end{array}
$$

is the exact solution

Now this example is solved numerically via the composite modified Trapezoidal rule. To do this, First the interval $[0,2]$ is divided into 9 subintervals such that

$\mathrm{x}_{\mathrm{i}}=\frac{2 \mathrm{i}}{9}, \quad \mathrm{i}=0,1, \ldots, 9$. Here $\mathrm{u}_{0}=$ $\mathrm{f}(0)=0$

$\operatorname{andk}(x, y)=x y$, then the equation(2) becomes:-

$$
\begin{gathered}
u_{i}=x_{i}+\frac{2}{45} \sum_{j=1}^{i-1} x_{i} x_{j} u_{j}+\frac{1}{45} x_{i}^{2} u_{i}, \\
i=1,2, \ldots, 9
\end{gathered}
$$

By evaluating the above equation at each $i=1,2, \ldots \ldots, 9$. one can get the following values

$$
\begin{aligned}
& \mathrm{u}_{2}=0.4473848062 \\
& \mathrm{u}_{5}=1.2202144860 \\
& \mathrm{u}_{8}=2.6002794255
\end{aligned}
$$

$$
\begin{array}{ll}
\mathrm{u}_{0}=0 & \mathrm{u}_{1}=0.1111263548 \\
\mathrm{u}_{3}=0.3342034914 & \mathrm{u}_{4}=0.4471361532 \\
\mathrm{u}_{6}=0.6801612311 & \mathrm{u}_{7}=0.8028363544 \\
\mathrm{u}_{9}=1.0694464177 & \mathrm{u}_{10}=1.2181872268 \\
\mathrm{u}_{12}=1.5627695728 & \mathrm{u}_{13}=1.7674153566
\end{array}
$$

$$
\begin{gathered}
u_{i}=x_{i}+\frac{1}{45} \sum_{j=1}^{i-1} x_{i} x_{j} u_{j}+\frac{1}{90} x_{i}^{2} u_{i}, i \\
=1,2, \ldots, 18(10)
\end{gathered}
$$

By evaluating the above equation at each $i=1,2, \ldots \ldots ., 18$. one can get the following values
$\mathrm{u}_{2}=0.2224052300$
$\mathrm{u}_{5}=0.5620744555$
$\mathrm{u}_{8}=0.9318755296$
$\mathrm{u}_{11}=1.3813145441$
$u_{14}=2.0013024661$ 
$\mathrm{u}_{15}=2.2720276405 \quad \mathrm{u}_{16}=2.5892200122 \quad \mathrm{u}_{17}=2.9652042709$

$\mathrm{u}_{18}=3.4159117144$

Third the interval $[0,2]$ is divided into 36 and 72 sub intervals, such that $\mathrm{x}_{\mathrm{i}}=\frac{\mathrm{i}}{18}, \mathrm{i}=0,1,2, \ldots, 36 \quad$ and $x_{i}=\frac{i}{36}, i=0,1,2, \ldots, 72$ respectively and some of these results are tabulated down with the comparison with the exact solution:-

Table (1) represents the exact and the numerical solutions of example (1) at specific points for different values of $n$

\begin{tabular}{|c|c|c|c|c|}
\hline \multirow{2}{*}{$\mathbf{X}$} & \multirow{2}{*}{ Exact Solution } & \multicolumn{3}{|c|}{ Numerical Solution } \\
\cline { 3 - 5 } & & Trap.N=9 & Trap.N=18 & Least square N=9 \\
\hline 0.222222222 & 0.2223848585 & 0.2224663554 & 0.2224052300 & 0.22233400 \\
\hline 0.444444444 & 0.4470533010 & 0.4473848062 & 0.4471361532 & 0.44703057 \\
\hline 0.666666667 & 0.6799663130 & 0.6807463739 & 0.6801612311 & 0.67997299 \\
\hline 0.888888889 & 0.9314983085 & 0.9330084342 & 0.9318755296 & 0.93153676 \\
\hline 1.111111111 & 1.2175126789 & 1.2202144860 & 1.2181872268 & 1.21758688 \\
\hline 1.333333333 & 1.5615934837 & 1.5663078835 & 1.5627695728 & 1.56171134 \\
\hline 1.555555556 & 1.9992459998 & 2.0074989850 & 2.0013024661 & 1.99941861 \\
\hline 1.777777778 & 2.5855576010 & 2.6002794255 & 2.5892200122 & 2.58580467 \\
\hline 2 & 3.4092097306 & 3.4362093627 & 3.4159117144 & 3.40956069 \\
\hline
\end{tabular}

Now the equation of the best line is found through the point for table (1) when $n=9$ by using Least square method.

$$
\begin{aligned}
f(a, b)=\sum_{i=1}^{9} y_{i}^{2} & +9 b^{2}+a^{2} \sum_{i=1}^{9} x_{i=1}^{2} \\
& -2 a \sum_{i=1}^{9} x_{i} y_{i} \\
& -2 b \sum_{i=1}^{9} x_{i} \\
& +2 a b \sum_{i=1}^{9} y_{i}
\end{aligned}
$$

$$
\begin{aligned}
=27.81001+ & 9 b^{2}+27.80505 a^{2} \\
& -55.61507 a \\
& -26.109903 b \\
& +26.1080356 a b
\end{aligned}
$$

In order to find $\mathrm{a}$ and $\mathrm{b}$ we equate $\frac{\partial f}{\partial a}$ and $\frac{\partial f}{\partial b}$ to zero

$$
\begin{gathered}
\frac{\partial f}{\partial a}=55.61011 a+26.1080356 b \\
-55.61507=0 \\
\begin{array}{rl}
\frac{\partial f}{\partial b}=18 b+2 & 26.1080356 a \\
& -26.109903 \\
& =0
\end{array}
\end{gathered}
$$

From eq. (13) we have 


$$
\mathrm{b}=\frac{26.109903}{18}-\frac{26.1080356}{18} \mathrm{a}
$$

$\mathrm{b}=1.450550514-1.45044622 \mathrm{a}(14)$

Substitute the value of $b$ in eq. (12) we have

$$
\begin{aligned}
55.61011 \mathrm{a}- & 37.86830683 \mathrm{a} \\
- & 55.61507 \\
& +37.87102447=0 \\
17.74180317 \mathrm{a}-17.74404553=0 & \\
\mathrm{a}=1.0001263 &
\end{aligned}
$$

Substitute the value of a in eq. (14) we have $b=-0.00007889$.

Then the point is $(1.0001263$, 0.00007889 ) and the equation of the beast line $\mathrm{y}=\mathrm{ax}+\mathrm{b}$ is $\quad \mathrm{y}=$ $1.0001263 \mathrm{x}-0.00007889$

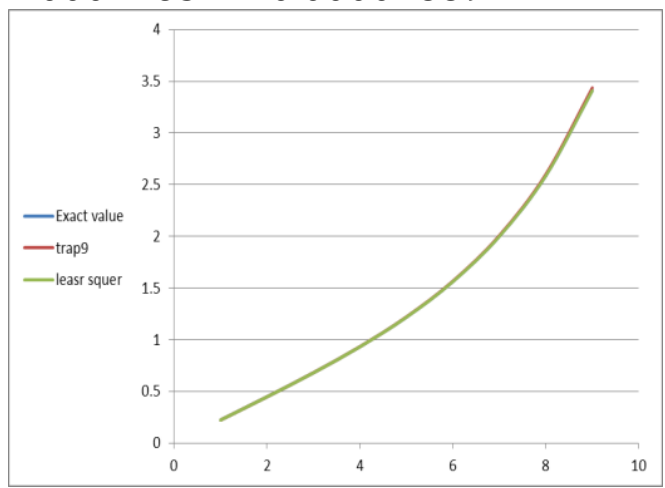

Fig (1)represent the equation $u(x)=x+\frac{1}{5} \int_{0}^{x} x y u(y) d y$ in three different methods

Table (2) represents the differences between exact and the numerical solutionsfor example1

\begin{tabular}{|c|c|c|c|c|c|}
\hline Exact Solution & $\begin{array}{c}\text { Numerical Solution } \\
\text { Trap.N=9 }\end{array}$ & $\begin{array}{c}\text { Numerical } \\
\text { Solution Least Seq. }\end{array}$ & $\begin{array}{c}\text { Exact\&trap. } \\
\text { difference }\end{array}$ & $\begin{array}{c}\text { Exact \&Least } \\
\text { seq. difference }\end{array}$ & $\begin{array}{c}\text { Trap.\&Leastseq } \\
\text { difference }\end{array}$ \\
\hline 0.22238480 & 0.222466355 & 0.22256156 & 0.000082 & 0.00005080 & 0.00013236 \\
\hline 0.44705300 & 0.447384806 & 0.44721647 & 0.000332 & 0.00002243 & 0.00035423 \\
\hline 0.67996600 & 0.68229191 & 0.68011568 & 0.0007804 & 0.00000699 & 0.00077338 \\
\hline 0.93149800 & 0.933049867 & 0.93163280 & 0.001510 & 0.00003876 & 0.00147168 \\
\hline 1.21751200 & 1.220268673 & 1.21762988 & 0.002702 & 0.00007488 & 0.00262760 \\
\hline 1.56159300 & 1.575270659 & 1.56169051 & 0.004715 & 0.00011834 & 0.00459654 \\
\hline 1.99924500 & 2.008454507 & 1.99931662 & 0.008254 & 0.00017361 & 0.00808037 \\
\hline 2.58555700 & 2.601517097 & 2.58559392 & 0.014722 & 0.00024767 & 0.01447476 \\
\hline 3.40920900 & 3.48408712 & 3.40919719 & 0.027000 & 0.00035169 & 0.02664867 \\
\hline
\end{tabular}

\section{Example (2):-}

Consider the one-dimensional Volterra linear integral equation of the second kind:-

$$
\begin{aligned}
u(x)=x-\frac{4}{35} & x^{7 / 2} \\
& +\int_{0}^{x}(x \\
& -y)^{3 / 2} u(y) d y \quad 0 \\
& \leq x \leq 2
\end{aligned}
$$

Using successive approximation method for solving this example taking the zeroth approximation $\mathrm{u}_{0}=\mathrm{x}$ Then

$u_{1}=x-\frac{4}{35} x^{7 / 2}+\int_{0}^{x}(x-y)^{3 / 2} y d y$

Using integral by parts to $\operatorname{solveu}_{1}(\mathrm{x})=\mathrm{x}-\frac{4}{35} \mathrm{x}^{7 / 2}-$ $\left.\frac{2}{5} y(x-y)^{\frac{5}{2}}\right)_{0}^{x}+\frac{2}{5} \int_{0}^{x}(x-y)^{\frac{5}{2}} d y$ 
$\left.=x-\frac{4}{35} x^{7 / 2}-\frac{4}{35}(x-y)\right)_{0}^{x}$

$=x-\frac{4}{35} x^{7 / 2}-\frac{4}{35} x^{7 / 2}=x=u_{0}$

.. $\quad \mathrm{u}_{0}=\mathrm{u}_{1}=\cdots=\mathrm{x}$

.. $\mathrm{u}(\mathrm{x})=\mathrm{x} \quad$ is the exact solution

Now this example is solved numerically via the composite modified Trapezoidal rule. To do this, First, the interval [0, 2]is divided into 9 subintervals such that

$x_{i}=\frac{2 i}{9}, \quad i=0,1, \ldots, 9$. Hereu $_{0}=$ $f(0)=0$ and $k(x, y)=(x-y)^{3 / 2}$.

Then equation (6) becomes:-
$\mathrm{u}_{0}=0$
$\mathrm{u}_{1}=0.2216310035$
$\mathrm{u}_{2}=0.4429149690$
$\mathrm{u}_{3}=0.6639218150$
$\mathrm{u}_{4}=0.8846406461$
$\mathrm{u}_{5}=1.1050205259$
$\mathrm{u}_{6}=1.3249767838$
$\mathrm{u}_{7}=1.5443897270$
$\mathrm{u}_{8}=1.7630994682$

By evaluating the above equation of each $\mathrm{i}=1,2, \ldots, 9$ one can get the following values:-

Second, if the interval $[0,2]$ is divided into 18 subintervals, such that

$$
x_{i}=\frac{i}{9}, \quad i=0,1, \ldots, 18 .
$$

the equation (6) becomes:-

By evaluating the above equation each $i=1,2, \ldots, 18$. One can get the following values.

$$
\begin{aligned}
u_{i}=x_{i}-\frac{4}{35} x_{i}{ }^{7 / 2} & \\
& +\frac{1}{9} \sum_{j=1}^{i-1}\left(x_{i}\right. \\
& \left.-x_{j}\right)^{3 / 2} u_{j}, \ldots i \\
& =1,2, \ldots, 18, \ldots
\end{aligned}
$$
$\mathrm{u}_{0}=0$
$\mathrm{u}_{1}=0.1110588543$
$\mathrm{u}_{2}=0.2220880359$
$\mathrm{u}_{3}=0.3330961478$
$\mathrm{u}_{4}=0.4440861641$
$\mathrm{u}_{5}=0.5550591943$
$\mathrm{u}_{6}=0.6660153189$
$\mathrm{u}_{7}=0.7769538948$
$\mathrm{u}_{8}=0.8878736889$
$\mathrm{u}_{9}=0.9987729386$
$\mathrm{u}_{10}=1.1096493733$
$\mathrm{u}_{11}=1.2205002125$
$\mathrm{u}_{12}=1.3313221472$
$\mathrm{u}_{13}=1.4421113071$
$\mathrm{u}_{14}=1.5528632159$
$\mathrm{u}_{15}=1.6635727341$
$\mathrm{u}_{16}=1.7742339905$
$\mathrm{u}_{17}=8848403004$

$\mathrm{u}_{18}=1.9876275257$

Third, if the interval $[0,2]$ is divided into 36 and 72 subintervals, such that $x_{i}=\frac{i}{18}, i=1,2, \ldots, 36$ and the $x_{i}=\frac{i}{36}, i=1, \ldots, 72$
Respectively and some of these results are tabulated down with the comparison with the exact solutions:-

Table (3) represents the exact and the numerical solutions of example (3) at specific points for different values of $\mathbf{n}$

\begin{tabular}{|c|c|c|}
\hline $\mathbf{X}$ & Exact Solution & Numerical Solution \\
\hline
\end{tabular}




\begin{tabular}{|c|c|c|c|c|}
\hline & & Trap.N=9 & Trap.N=18 & Least square N=9 \\
\hline 0.222222222 & 0.2222222222 & 0.2216310035 & 0.2220880359 & 0.22222222 \\
\hline 0.444444444 & 0.4444444444 & 0.4429149690 & 0.4440861641 & 0.44444444 \\
\hline 0.666666667 & 0.6666666667 & 0.6639218150 & 0.6660153189 & 0.66666667 \\
\hline 0.888888889 & 0.8888888889 & 0.8846406461 & 0.8878736889 & 0.88888889 \\
\hline 1.111111111 & 1.1111111111 & 1.1050205259 & 1.1096493733 & 1.11111111 \\
\hline 1.333333333 & 1.3333333333 & 1.3249767838 & 1.3313221472 & 1.33333333 \\
\hline 1.555555556 & 1.5555555556 & 1.5443897270 & 1.5528632159 & 1.55555556 \\
\hline 1.777777778 & 1.7777777778 & 1.7630994682 & 1.7742339905 & 1.77777778 \\
\hline 2 & 2.0000000000 & 1.9808975240 & 1.9876275257 & 2.00000000 \\
\hline
\end{tabular}

In the same way in example (1) the equation of the best line is found by least square method and the values of $a$ and $b$ are 1 and 0 respectively, and the equation is $y=a x+b$ is $y=x$

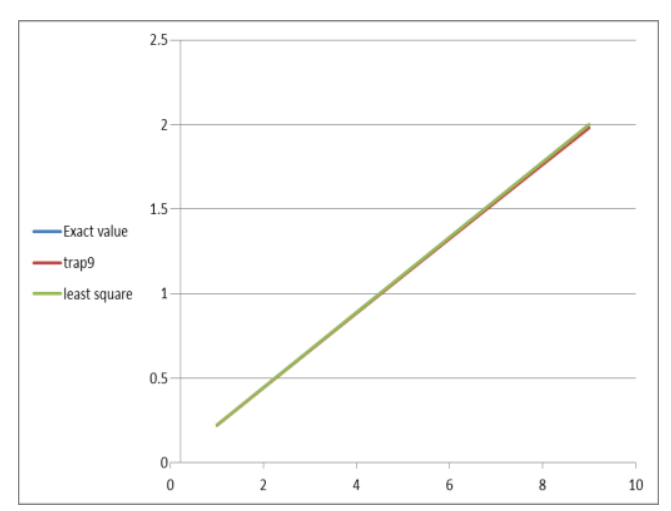

Fig (2): represent the equationu $(x)=$ $x-\frac{4}{35} x^{7 / 2}+\int_{0}^{x}(x-y)^{\frac{3}{2}} u(y) d$ yin three different method

Table (4) represents the differences between exact and the numerical solutionsfor example(2)

\begin{tabular}{|c|c|c|c|c|c|}
\hline Exact Solution & $\begin{array}{c}\text { Numerical Solution } \\
\text { Trap.N=9 }\end{array}$ & $\begin{array}{c}\text { Numerical } \\
\text { Solution Least Seq. }\end{array}$ & $\begin{array}{c}\text { Exact\&trap. } \\
\text { difference }\end{array}$ & $\begin{array}{c}\text { Exact \&Least } \\
\text { seq. difference }\end{array}$ & $\begin{array}{c}\text { Trap.\&Leastseq } \\
\text { difference }\end{array}$ \\
\hline 0.2222222 & 0.2216310 & 0.22239899 & 0.0005912 & 0 & 0.000591219 \\
\hline 0.4444444 & 0.4429150 & 0.44460806 & 0.0015295 & 0 & 0.001529475 \\
\hline 0.6666667 & 0.6639218 & 0.66681714 & 0.0027449 & 0 & 0.002744852 \\
\hline 0.8888889 & 0.8846406 & 0.88902621 & 0.0042482 & 0 & 0.004248243 \\
\hline 1.1111111 & 1.1050205 & 1.11123528 & 0.0060906 & 0 & 0.006090585 \\
\hline 1.3333333 & 1.3249768 & 1.33344435 & 0.0083565 & 0 & 0.008356549 \\
\hline 1.5555556 & 1.5443897 & 1.55565343 & 0.0111658 & 0 & 0.011165829 \\
\hline 1.7777778 & 1.7630995 & 1.77786250 & 0.0146783 & 0 & 0.01467831 \\
\hline 2 & 1.9808975 & 2.00007157 & 0.0191025 & $0.000 \mathrm{E}+00$ & 0.019102476 \\
\hline
\end{tabular}

\section{References:}

1. Al-Jubory A. K. 2004," Numerical Techniques for Special Type of Integral Equations," M. Sc. Thesis, University of Technology,

2. Jerri A. 1985," Introduction to Integral Equations with Applications ", Marcel Dekker.

3. Maleknejad K. and Aghazadeh N.,2005,"Numerical Expansion Methods for Solving Integral Equations by Interpolation and Gauss Quadrature Methods", Appl. Math. and Comput.168(1):111-124.

4. Maleknejad K. and Aghazadeh N.,(2005),"Numerical Solution of Volterra Integral Equations of the $2^{\text {nd }}$ kind with Convolutions Kernel by Using Taylor Series Expansion Method", Appl. Math. andComput. , 161(1):915-922

5. Sahri-NadjafiJafar and Heidari Mahdi. 2007,"Solving Liner Integral Equations of the $2^{\text {nd }}$ Kind with Repeated Modified Trapezoidal Quadrature Method “, Appl. Math. andComput. , 189(1):980-985.

6. Jafarian A. , Esmailzadeh Z. and Khoshbakhti L., 2013,"A Numerical Method for Solving Non Linear Integral Equations in the Urysohn Form", Appl. Math. Scie. ,(28):1375-1385. 
7. Oliveira S.P and Ruiz de Zarate A., 2013,"A note on the alternate trapezoidal quadrature method F. I. eigen value problems", Numerical Algorithm No.62:601-614.

8. Rashidinia j, M. and Zahra.2013,"Collocation Method is Used for Solving Fredholm and Volterra Integral Equation “, The
International Journal of Systems and Cybernetics", 42(3):400-412.

9. Al-Sa'dany, Sh. M. 2008," Some Modified quadrature methods for solving systems of voltrra linear Integral equations," M. Sc., Thesis, Ibnal-haithm College-University of Baghdad.

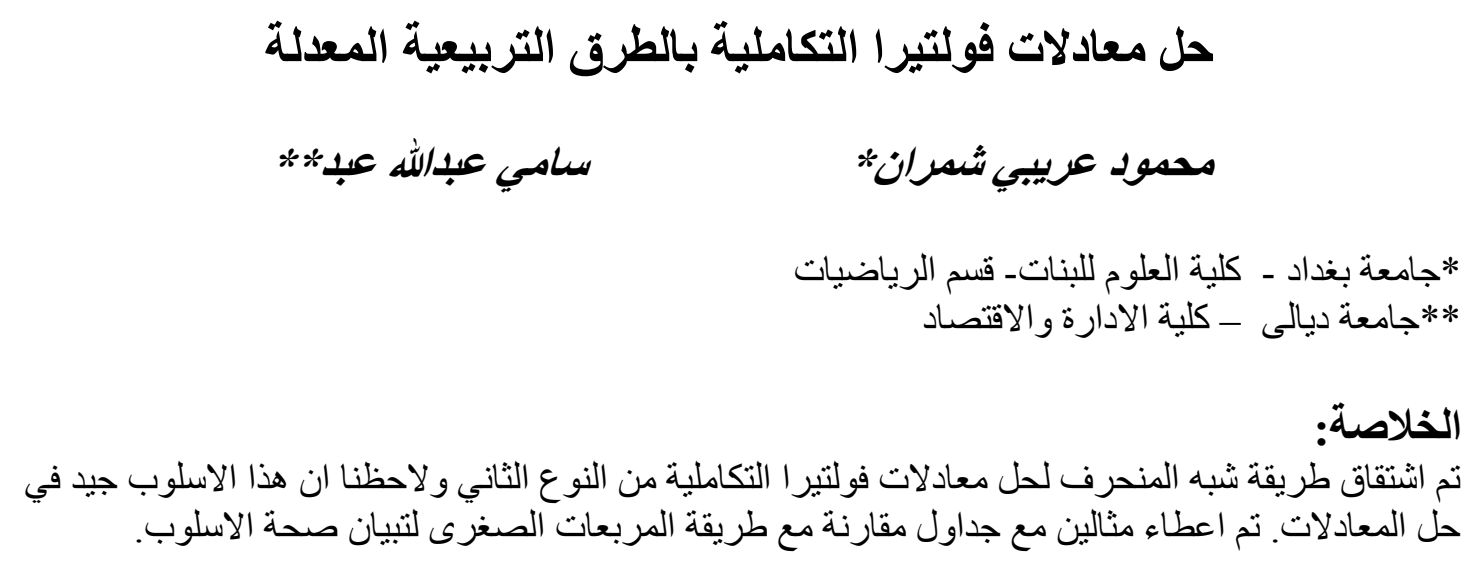

